Jul 1st, 12:00 AM

\title{
Implications of processing spatial data from a forested catchment for a hillslope hydrological model
}

Teemu Kokkonen

Harri Koivusalo

A. Laurén

S. Penttinen

S. Piirainen

See next page for additional authors

Follow this and additional works at: https://scholarsarchive.byu.edu/iemssconference

Kokkonen, Teemu; Koivusalo, Harri; Laurén, A.; Penttinen, S.; Piirainen, S.; Starrd, M.; and Finér, L., "Implications of processing spatial data from a forested catchment for a hillslope hydrological model" (2004). International Congress on Environmental Modelling and Software. 57.

https://scholarsarchive.byu.edu/iemssconference/2004/all/57

This Event is brought to you for free and open access by the Civil and Environmental Engineering at BYU ScholarsArchive. It has been accepted for inclusion in International Congress on Environmental Modelling and Software by an authorized administrator of BYU ScholarsArchive. For more information, please contact scholarsarchive@byu.edu, ellen_amatangelo@byu.edu. 


\section{Presenter/Author Information}

Teemu Kokkonen, Harri Koivusalo, A. Laurén, S. Penttinen, S. Piirainen, M. Starrd, and L. Finér 


\title{
Implications of processing spatial data from a forested catchment for a hillslope hydrological model
}

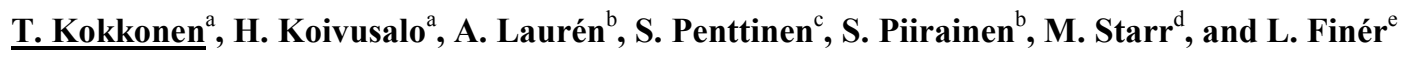 \\ ${ }^{a}$ Laboratory of Water Resources, Helsinki University of Technology; tkokko@cc.hut.fi \\ ${ }^{\mathrm{b} J o e n s u u}$ and ${ }^{\mathrm{d}}$ Vantaa Research Centres, Finnish Forest Research Institute \\ ${ }^{\mathrm{c}}$ Kuopio Office, Geological Survey of Finland \\ ${ }^{\mathrm{e}}$ Faculty of Forestry, University of Joensuu
}

\begin{abstract}
Finland has committed to both increasing timber production and decreasing the nutrient loading caused by forestry, which calls for development of methods to assess environmental impacts of forest management. A simulation model based on the concept of a typical hillslope is applied to describe water and nitrogen processes in a forested catchment. Application of the model requires that spatially distributed catchment data are processed to create parameterisation for a vertical two-dimensional profile. In such a twodimensional catchment description, behaviour of the system at different distances to a stream can be considered. This study explores 1) how changing the location of a clear-cut area is reflected in model results, and 2) how the inevitable simplifications when representing a catchment as a single hillslope may affect the model outcome. The results suggest that description of the catchment with a single two-dimensional profile is a reasonable approximation as long as areas having a high fraction of subsurface runoff ( $>60-70 \%)$ are not combined with areas where the surface runoff component is dominant. At low hydraulic conductivities the nitrate load was strongly controlled by the distance from the cut area to the stream, and the load increased almost linearly with the inverse of the distance. But when the conductivity value became sufficiently large, the effect of the cutting location became smaller, and the relationship to the inverse of the distance was obscured by snowmelt timing differences in open and forested environments.
\end{abstract}

Keywords: Catchment; Forest harvesting; Hydrology; Nitrate; Mathematical modelling; Spatial description

\section{INTRODUCTION}

Environmental impacts of forest management practises are particularly important to countries like Finland, where $75 \%$ of the land area is covered with forests and $84 \%$ of those forests are managed for timber production (Finnish Forest Research Institute, 2002). At the national level, forest management contributes ca. $9 \%$ of the nitrogen load to surface waters (Kenttämies, 2003). Locally forest management can be the most significant human activity responsible for nutrient leaching to lakes and rivers. Finland has committed to increase timber production and to decrease the nutrient loading caused by forestry (Ministry of Agriculture and Forestry, 1999). These controversial aims will require development of computation methods to support the forest manager in planning treatments in such a manner that the environmental loading is minimised.

The aim of this paper is first to explore how a hydrological model based on the concept of a typical hillslope can exploit distributed data depicting topography and land-use of a first-order headwater catchment. The inevitable simplifications when representing a catchment as a single hillslope are discussed and assessed. The model is finally used to assess how the location of a clear-cut area is reflected in nitrate export.

\section{METHODS}

\subsection{Two-dimensional description of a} catchment

In the present study implications of simplifying the three-dimensional catchment domain into two dimensions are explored. The simplification relies on the concept of a characteristic profile, which is defined to represent a typical flowpath from a water divide into the nearest stream (Kokkonen et al., 2001).

Determination of the surface geometry of a characteristic profile, i.e. length and slope, is based on an analysis of the digital elevation model of a catchment. The elevation difference between each pixel and its receiving stream pixel is computed, 
and these differences are categorised according to the distance from the stream along the flowpath. Average value of the elevation differences at a given distance determines the elevation of the profile at that distance. Convergent or divergent topography within the catchment is accounted for with the aid of a width function. The width distribution along the profile is identified from the number of pixels located at a given distance. More information on how the characteristic profile is determined can be found in Kokkonen et al. (2001) and Koivusalo et al. (2003).

\subsection{Hydrological modelling}

The characteristic profile model (CPM) applied in this study comprises separate routines for estimating meteorological variables beneath the canopy (Koivusalo and Kokkonen, 2002), calculating accumulation and melt of a snowpack (Koivusalo et al., 2001), and describing soil water movement and runoff generation processes along a typical hillslope (Karvonen et al., 1999). The canopy and snow routines operate at an hourly time-step, and the runoff generation procedure operates at a daily time scale. The model has been developed for areas where shallow soils $(1-3 \mathrm{~m})$ are underlain by an impermeable bedrock, and where the infiltration capacity of the soil exceeds the intensity of rainfall or snowmelt.

The characteristic profile is divided into vertical soil columns, which are further divided into soil layers. Vertical fluxes in all columns are computed by the Skaggs (1980) approximation to the Richards equation. Water that cannot infiltrate is transported downslope the profile as surface runoff and it either reaches the stream, or infiltrates if the air volume further down the profile allows it. After the vertical fluxes and the resulting groundwater levels have been resolved, lateral groundwater flow between soil columns is computed from Darcy's law. The groundwater flow from the column adjoining the stream forms one of the runoff components and is later called groundwater flow. When the groundwater level in any column rises above the soil surface, the model generates exfiltration runoff which is transported downslope in a similar manner as surface runoff. Groundwater flow and exfiltration runoff together form that part of runoff that has infiltrated into the soil before getting discharged into the stream. The sum of these two runoff components is later referred to as subsurface runoff.

Hydrological effects of a forest cutting are described by bypassing the canopy model. Koivusalo et al. (2003) have demonstrated the performance of the model against field data measured in Kangasvaara.

\subsection{Nitrogen modelling}

Nitrogen demand of the tree stand is linearly related to the rate of photosynthesis, which is estimated with the FINNFOR forest ecological model (Kellomäki and Väisänen, 1997). FINNFOR also simulates the canopy litter-fall to the ground, which forms the input to a litter decomposition routine modified from the ROMUL model (Chertov et al., 2001). Nitrogen released from decomposing litter together with the atmospheric deposition of nitrogen form the nitrogen input to the CPM. Nitrogen is transported along a characteristic profile according to the water fluxes computed in the CPM. Process descriptions for nitrification, denitrification and retention have been adopted from Jansson and Karlberg (2001). While the current model accounts for nitrate, ammonium, and dissolved organic nitrogen processes, only the nitrate results are addressed in the present study.

The effect of clear-cutting on nitrogen processes is described as decreased plant demand and as an instantaneous litter input in the form of logging residues.

\section{SITE AND DATA DESCRIPTION}

The study utilises meteorological data at the Kangasvaara ( $56 \mathrm{ha}$ ) catchment located in eastern Finland ( $\left.63^{\circ} 51^{\prime} \mathrm{N}, 28^{\circ} 58^{\prime} \mathrm{E}\right)$. This catchment was instrumented as part of the VALU project commencing in 1992 (Finér et al. 1997). Meteorological data covering the period from 1992 to 2001 were compiled from both on-site measurements and records obtained from the nearest (ca. $20 \mathrm{~km}$ ) weather station operated by the Finnish Meteorological Institute. The forests in Kangasvaara were dominated by mature coniferous trees. In late 1996 a total of $35 \%$ of the catchment area was clear-cut. In Kangasvaara 92\% of the area is covered by glacial till, while the remaining land area is covered by peat.

Long-term mean annual precipitation and air temperature in the area are $700 \mathrm{~mm}$ and $1.5{ }^{\circ} \mathrm{C}$, respectively. The bulk nitrate deposition was 101 $\mathrm{kg}-\mathrm{N} / \mathrm{km}^{2} / \mathrm{a}$ in the period from 1993 to 1996 (Piirainen et al., 1998), and the mean annual nitrate export was in the order of $2 \mathrm{~kg}-\mathrm{N} / \mathrm{km}^{2} / \mathrm{a}$ before the harvest. A few years after the clear-cut nitrate concentrations have significantly increased (Ahtiainen et al., 2003).

For the model simulations presented in Section 4 a reference profile, which reflects the average topography and soil depths in the Kangasvaara catchment, was created. The reference profile, discretised into 20 columns, has a length of $500 \mathrm{~m}$, a constant width, a slope of $6^{\circ}$, a depth of $1.5 \mathrm{~m}$, and a $100 \%$ forest cover. 


\section{RESULTS AND DISCUSSION}

\subsection{Possibilities and compromises of a two- dimensional catchment description}

The presented vertical two-dimensional representation of a catchment allows consideration of horizontally distributed catchment properties (e.g. topography and clear-cut locations) as a function of distance from the stream. Also, the travel distance of water and solutes to the stream and different moisture conditions along the flowpath can be taken into account in such a simplified catchment representation. This contrasts with models that have a lumped catchment representation.

However, the simplification of the three dimensional catchment domain into two dimensions inevitably results in a loss of information, which may have consequences that are not obvious. When values of catchment properties depend only on the distance to a stream, no information is lost even though one dimension is omitted. In such an ideal setting the spatial distribution of catchment properties can be fully described in a single characteristic profile. In any real catchment such symmetry does not exist, and information is lost through averaging variables that define the profile shape, assigning values for class variables along the profile, and changing the connectivity structure of catchment sub-areas having different properties.

Two profiles with different properties, such as slope, can justifiably be aggregated together to form a single characteristic profile, when the model response is linear with respect to that property. However, when this linearity requirement is violated, the model output from the single profile differs from the sum of outputs from the two profiles. Class variables, such as vegetation type and soil type, can only have one value in the characteristic profile at a given distance from the stream, even though several classes may exist at the same distance. Assigning a single value for a class variable at any distance along the characteristic profile may distort the structure how areas with different properties drain through each other. The connectivity structure may also be distorted by aggregating short hillslopes with the near-stream parts of longer hillslopes, which in essence increases the downslope width of the single profile.

In the following simulations response of the model output to changes in location of a clear-cut area ( $35 \%$ of the total area), slope of the profile, and length of the profile is studied by varying one of those parameters at a time. Previous applications of the CPM have shown that the lateral hydraulic conductivity value of soil has an important role in determining the fraction of subsurface runoff (Koivusalo and Kokkonen, 2003). Therefore, the model response to changes in the above parameters is studied across conductivity values ranging from 0.1 to $50 \mathrm{~cm} / \mathrm{h}$. Otherwise, the soil hydraulic parameters were adopted from Möttönen (2000).

As the runoff generation mechanism and leaching of nitrate are likely to be related, the model response is assessed in terms of the fraction of subsurface runoff and the average annual nitrate load.

\subsection{Location of a clear-cut area}

Figure 1a shows how the subsurface runoff fraction changes when the distance between the centre of the clear-cut area and the stream decreases from 413 to $88 \mathrm{~m}$. When the distance is at its minimum the cut area resides next to the stream. At low lateral conductivity values the location of the clear-cut had no effect on the subsurface runoff percentage, but when the conductivity value was increased a profile with a clear-cut area close to the water divide produced less subsurface runoff than a profile where a clearcut area was located next to the stream. This model result is explained by the earlier melt of snow in the cut than in the forested parts of the profile. In the model only subsurface flow is delayed along the profile, while surface runoff reaches the stream within one computation time-step independent of the distance. When the subsurface runoff component dominates the transport of water along the profile, a certain combination of hydraulic conductivity and distance to a stream can lead to a situation where melting waters from the clear-cut areas located further upslope on the profile reach the stream at the same time as snow melts in forest areas near the stream. This leads to an increased saturation in the near stream areas, which causes more surface runoff to be generated.

Changes in nitrate export resulting from varying location of the clear-cut area are presented in Figure $1 \mathrm{~b}$. When the fraction of surface runoff is high, and the conductivity is low, nitrate loads increase almost linearly with the inverse of distance to the stream until the minimum value is reached. The nitrate load is much more sensitive to the cutting location at low than at high conductivities. At the highest tested conductivity value the nitrate load did not reach the minimum value when the clear-cut area is furthest away from the stream. This perhaps counterintuitive finding is explained by the behaviour of the subsurface runoff fraction as explained earlier. 
a)

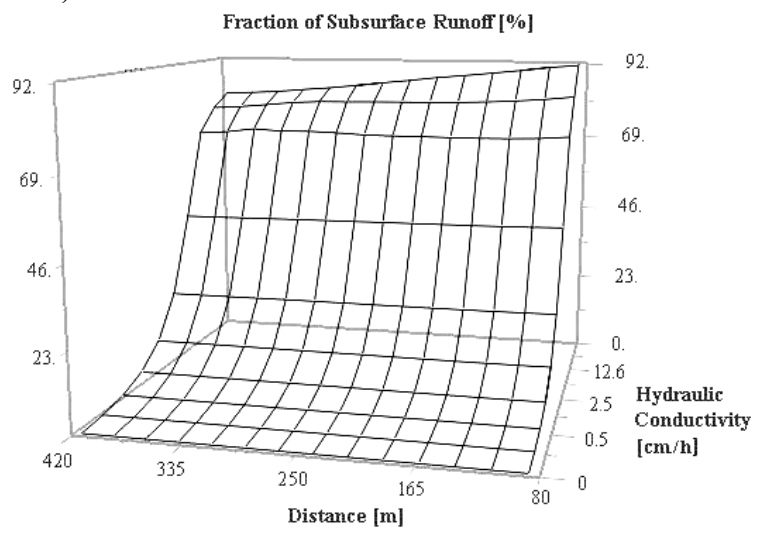

b)

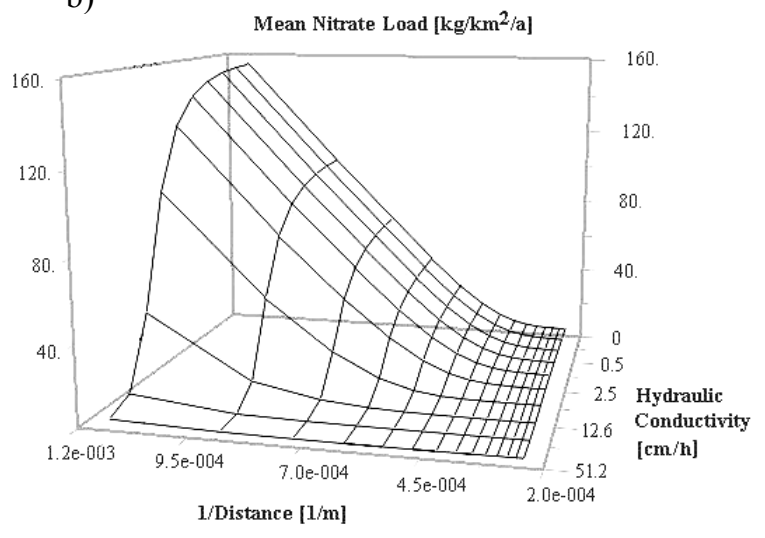

Figure 1. Fraction of subsurface runoff as a function of the mean distance between the stream and the clear-cut area (a) and the mean nitrate load as a function of the inverse of distance (b).

\subsection{Profile slope and profile length}

Figure $2 \mathrm{a}$ shows how the fraction of subsurface runoff is related to the slope of the profile. With increasing slope the share of subsurface runoff increases, particularly for soils with high conductivities and gentle slopes. This dependency is nearly linear until a subsurface runoff fraction of $60-70 \%$ is reached. After this the fraction gradually approaches the maximum value of $100 \%$ as the profile becomes steeper. On the contrary to the fraction of subsurface runoff, the nitrate export decreased with the increase of the profile slope (Figure 2b). In fact, the fraction of subsurface runoff and the annual nitrate load showed a strong negative correlation $(R=-0.99)$.

Increasing the profile length led to a decrease in the fraction of subsurface runoff (Figure 3). This is a reflection of an increasing upslope area that drains into a stream through an equal width at the downslope end of the profile. The decrease of the subsurface flow fraction is almost linearly related to the inverse of the profile length until the fraction becomes sufficiently large $(60-70 \%)$. The nitrate load has again almost a perfect negative correlation $(\mathrm{R}=-0.99)$ with the fraction of subsurface flow. This can be seen as a decrease in nitrate export with the inverse of profile length.
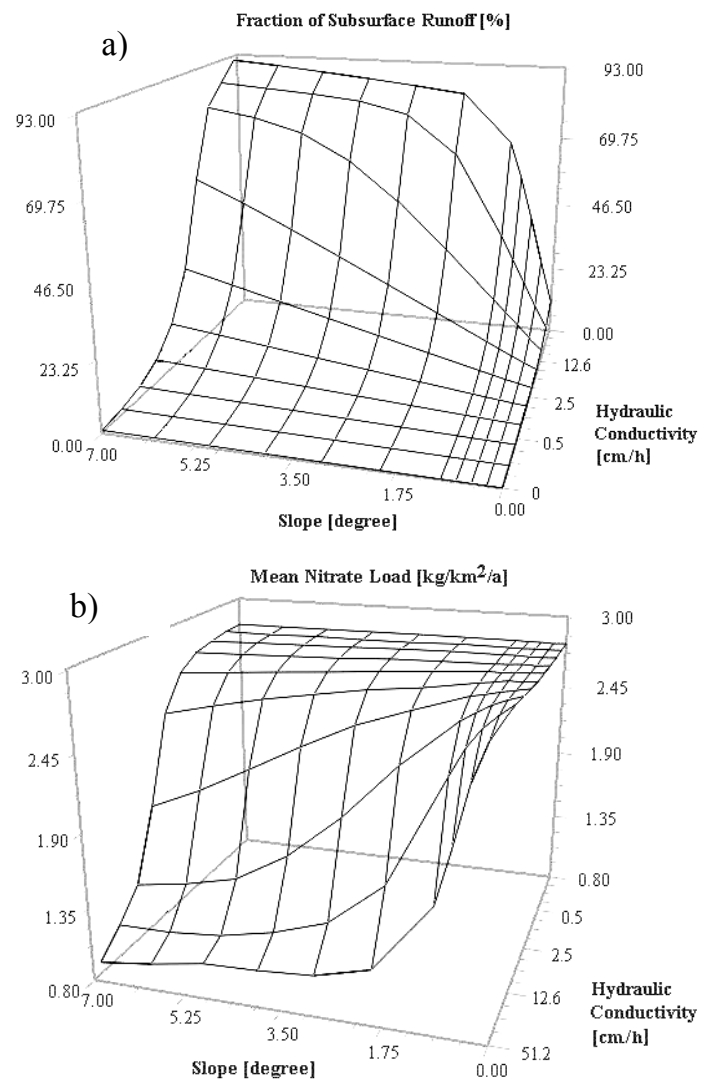

Figure 2. Fraction of subsurface runoff (a) and mean nitrate load (b) as a function of slope.

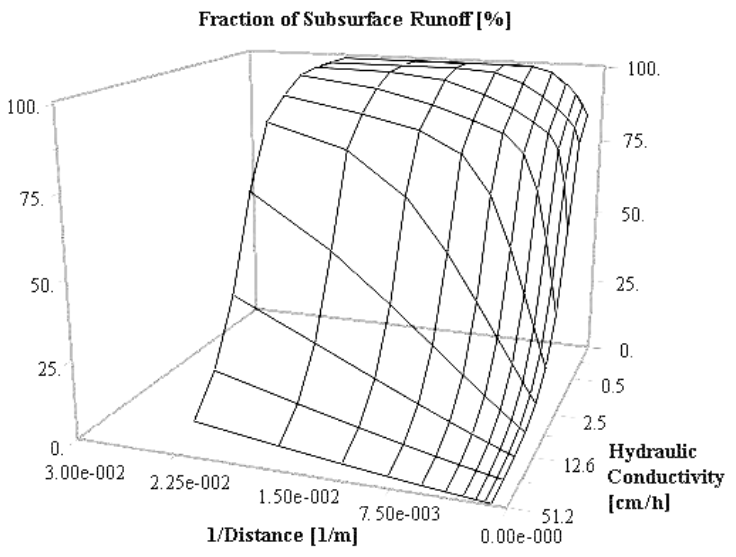

Figure 3. Fraction of subsurface runoff as a function of profile length.

The effect of width distribution of equally long profiles on the fraction of subsurface runoff depends on the runoff generation mechanism. When groundwater flow is the dominant mechanism producing subsurface runoff, the width distribution has a similar effect as the profile length, i.e. expansion of the upslope area by increasing the profile convergence decreases the fraction of subsurface runoff. However, 
exfiltration runoff, which is initiated when the profile convergence becomes sufficiently large, has a compensating effect on the amount of subsurface runoff. Increasing the profile convergence, as opposed to groundwater flow, led to a greater amount of exfiltration runoff. Therefore, after exfiltration runoff is activated, the fraction of subsurface flow is insensitive to a change in the profile convergence.

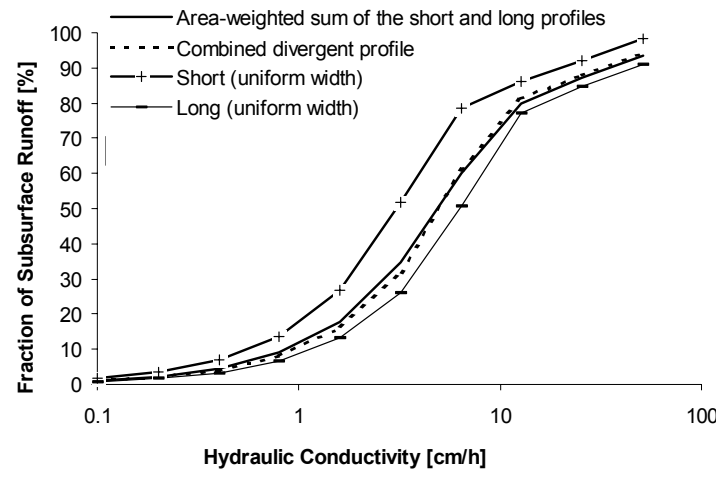

Figure 4. Fraction of subsurface runoff as a function of lateral hydraulic conductivity for four different cases. The short $(250 \mathrm{~m})$ and long (500 m) profiles represent $1 / 3$ and $2 / 3$ of the catchment area, respectively.

The effect of breaking the connectivity structure of different areas within a catchment was studied with the following simulation example. A catchment with one side of the stream having short hillslopes and the other side having long hillslopes was modelled first with two constant width profiles. Subsequently, the same catchment was represented with one divergent profile. According to the results (Figure 4), the two model set-ups gave nearly identical values for the fraction of subsurface runoff across the range of tested conductivities. Because the simulated nitrate load correlated strongly with the subsurface runoff fraction, there was also little difference in nitrate export values for the two cases.

\section{CONCLUSIONS}

Results indicated that the nitrate load showed a strong linear relationship with the fraction of subsurface runoff. The share of subsurface runoff, however, showed a non-linear behaviour with the profile length and slope.

Simulation results depicting the influence of the profile slope on the runoff generation mechanism revealed that the slope angle had a nearly linear control on the subsurface runoff fraction when the fraction remained below $60-70 \%$. The averaging of profiles having different slopes into a single profile can be justified under such conditions. But when profiles producing large fractions of subsurface flow are aggregated with profiles generating only little subsurface runoff, the assumption of linearity is violated and the averaging procedure leads to an overestimation of the subsurface fraction.

Aggregating profiles with different lengths distorts the connectivity structure of the catchment as the short profiles are combined with the near-stream parts of longer hillslopes. With uniform soils and land-use (forest), however, it did not matter whether the catchment was described with two parallel profiles of different length and uniform width or with a single divergent profile having the same length as the longer of the two profiles. Breaking the structure how catchment sub-areas connect with each other is likely to have a more pronounced effect when some areas within the catchment have significantly different characteristics. This is the case, for example, when the catchment has been subject to clear-cutting or has soils with varying hydraulic characteristics and vegetation cover.

Despite the inevitable simplifications that arise when representing a catchment as a single hillslope, the two-dimensional framework for assessing environmental impacts of forest management practises offers advantages over a lumped, one-dimensional catchment description. The model structure based on a characteristic profile can accommodate the effects of slope angle and length of the profile, and also the effects of location of a cut area. Simulation of the effects of clear-cutting indicated that at low soil conductivities, nitrate loads increased linearly with the inverse of distance between the cut area and the stream. But when the conductivity value became sufficiently large, effects arising from differences in the timing of snowmelt between open and forested environments obscured this relationship.

Although not all assumptions incorporated in the current version of the model may be accurate, the two-dimensional catchment description provides a framework where hypotheses about clear-cutting effects can be evaluated and tested. In a complex forest ecosystem, where the controls are not necessarily straightforward and intuitive, a simulation model can be a valuable tool in analysing and interpreting field measurements.

\section{ACKNOWLEDGEMENTS}

This work was funded by the Academy of Finland project FEMMA (No 52740), which develops tools for assessing environmental impacts of forest management practises. On-site hydrometeorological data were collected in the VALU project. Additional meteorological data were 
kindly provided by the Finnish Meteorological Institute. Support from prof. Pertti Vakkilainen, prof. Tuomo Karvonen, prof. Hannu Mannerkoski, Dr. Keijo Nenonen, and Dr. Pekka Hänninen is greatly acknowledged.

\section{REFERENCES}

Ahtiainen, M., L. Finér, M. Haapanen, K. Kenttämies, T. Mattsson, and A. Rämö, Näkyvätkö hakkuun ja maanmuokkauksen vaikutukset valumaveden laadussa tehoavatko ympäristönsuojeluohjeet? (in Finnish) In: L. Finér, A. Laurén, and L. Karvinen (eds.), Proceedings of the Koli Seminar, Research Papers 886, Finnish Forest Research Institute, 25-33, Joensuu, 2003.

Chertov, O.G., A.S. Komarov, M. Nadporozhskaya, S.S. Bykhovets, and S.L. Zudin, ROMUL - a model of forest soil organic matter dynamics as a substantial tool for forest ecosystem modelling, Ecological Modelling, 138, 289-308, 2001.

Finér, L., M. Ahtiainen, H. Mannerkoski, V. Möttönen, S. Piirainen, P. Seuna, and M. Starr, Effects of harvesting and scarification on water and nutrient fluxes, Research Papers 648, Finnish Forest Research Institute, 38 p., Joensuu, 1997.

Finnish Forest Research Institute, Statistical Yearbook of Forestry 2002, Finnish Forest Research Institute, 2002.

Jansson, P.-E. and L. Karlberg, Coupled heat and mass transfer model for soil-plantatmosphere systems, Royal Institute of Technology, Dept. of Civil and Environmental Engineering, 321 pp. Stockholm, 2001.

Karvonen, T., H. Koivusalo, M. Jauhiainen, J. Palko, K. Weppling, A hydrological model for predicting runoff from different land use areas, Journal of Hydrology, 217, 253-265, 1999.

Kellomäki, S., and H. Väisänen, Modelling the dynamics of the forest ecosystem for climate change studies in the boreal conditions, Ecological Modelling, 97, 121140, 1997.

Kenttämies, K., Tilanne ja tavoitteet metsätalouden vesistökurmituksen vähentämiseksi (in Finnish), In: L. Finér, A. Laurén, and L. Karvinen (eds.), Research Papers 886, Finnish Forest Research Institute, 2003.
Koivusalo, H., and T. Kokkonen, Snow processes in a forest clearing and in a coniferous forest, Journal of Hydrology, 262, 145-164, 2002.

Koivusalo, H., and T. Kokkonen, Snow processes in a forest clearing and in a coniferous forest, Journal of Hydrology, 262, 145-164, 2002.

Koivusalo, H., and T. Kokkonen, Modelling runoff generation in a forested catchment in southern Finland, Hydrological Processes, 17, 313-328, 2003.

Koivusalo, H., M. Heikinheimo, and T. Karvonen, Test of a simple two-layer parameterisation to simulate the energy balance and temperature of a snowpack, Theoretical and Applied Climatology, 70, 65-79, 2001.

Koivusalo, H., T. Kokkonen, A. Laurén, M. Ahtiainen, T. Karvonen, H. Mannerkoski, S. Penttinen, P. Seuna, M. Starr, P. Vakkilainen, and L. Finér, Parameterisation and application of a hillslope model to assess hydrological impacts of forest harvesting, In: D. Post (ed.), MODSIM 2003. The Modelling and Simulation Society of Australia and New Zealand, Townsville, Australia, 855, 2003.

Kokkonen, T., H. Koivusalo, T. Karvonen, A semi-distributed approach to rainfall-runoff modelling - a case study in a snow affected catchment, Environmental Modelling \& Software, 16, 481-493, 2001.

Ministry of Agriculture and Forestry, Finland's National Forest Programme 2010, Publications 2/1999, Ministry of Agriculture and Forestry, 1999.

Möttönen, V., Moreenin vesitaloustunnusten vaihtelu tuoreessa kangasmetsässä ennen hakkuuta ja hakkuun jälkeen (in Finnish), Lic. For. Thesis, University of Joensuu, Faculty of Forestry, 56 p., Joensuu, 2000.

Piirainen, S., L. Finér, and M. Starr, Canopy and soil retention of nitrogen deposition in a mixed boreal forest in eastern Finland, Water, Air, and Soil Pollution, 105, 165174, 1998.

Skaggs, R.W., A water management model for artificially drained soils, North Carolina Agricultural Research Service, 54 p., Raleigh, 1980. 